\title{
A trajetória de vida das mulheres judias, sobreviventes do Holocausto: relatos orais
}

The Trajectory of Women's lives Jewish Holocaust Survivors: Oral Reports

\section{Lilian Ferreira de Souza*}

Resumo: A partir do registro dos relatos orais sobre o Holocausto, pretendemos analisar testemunhos que expressem as trajetórias das mulheres sobreviventes do nazismo. Como critério, optamos pelas narrativas daquelas que passaram por guetos, campos de concentração e/ ou trabalho forçados. O foco está nas histórias de vida daquelas que escolheram o Brasil como comunidade de destino pressionadas pela política antissemita endossada pelo Terceiro Reich e países colaboracionistas que previam a "Solução Final" para o povo judeu. Assim, os registros dos testemunhos têm como objetivo documentar essas narrativas redimensionadas à luz de documentos pessoais. Para nós intermediários e interlocutores - esse exercício de reflexão ajudará a (re)pensar a sociedade que, ainda hoje, convive com novos genocídios.

Palavras-chave: Mulher. Holocausto. História oral.

Abstract: Having as a starting point the Holocaust oral narratives recordings, this work aims to analyze the trajectories of testimonials from Nazism's women survivors. As selection criteria we chose those who experienced the concentration camps and forced labor, ghettos and those who acted in resistance fronts as partisans. The focus will be the life story of those who chose Brazil as a destination community, pressured by the anti-Semitic National Socialist German Party that sought the "final solution" to the Jewish people. Therefore the testimonials recordings aims to document these narratives resized in the spotlight of personal documents. To us-intermediaries and interlocutorsthe reflection exercise helps to (re)think society, that today lives with new genocides.

Keywords: Woman. Holocaust. Oral History.

A historiografia sobre o tema revela que um número expressivo de mulheres judias foram perseguidas, torturadas e confinadas em espaços de exclusão: guetos, campos de trabalho e de extermínio. Após a ascensão de Adolf Hitler ao poder em 1933 na Alemanha, o Estado alemão decretou gradativamente uma série de leis que classificavam os judeus e demais minorias raciais como seres inferiores, sub-humanos. ${ }^{1}$ Tratadas como representantes de uma raça degenerada, as mulheres judias, especialmente, tiveram o percurso de suas 
vidas alterado por normas e ações racistas previstas como parte do plano de exclusão e extermínio idealizado pelo Terceiro Reich.

De acordo com as teorias antissemitas em voga na Alemanha e endossadas pelos países colaboracionistas, as mulheres judias - segundo o discurso nazista, eram consideradas impuras e portadores de sangue contaminado. Como tais não estavam aptas a serem cidadãs alemãs, fundamento que justificava o banimento sistemático da sociedade. As evidências dessas práticas são um dos focos deste artigo que buscou, por meio das narrativas femininas, registrar o significado de ser mulher na Alemanha nazista e nos países sob ocupação. ${ }^{2}$

Ser mulher judia na Alemanha, a partir de 1933, tornou-se sinônimo de reprodutora da raça inferior. O Estado, influenciado pela eugenia, procurou controlar a taxa de natalidade de determinados segmentos da população, principalmente os judeus e os ciganos, adotando programas de esterilização forçada. Cumpre ressaltar que as esterilizações e outras formas hediondas de experiências científicas empreendidas pelos médicos do Terceiro Reich não distinguiam os pacientes segundo o gênero. Entretanto, entendemos que a prática da esterilização atingia as mulheres de forma bastante traumática, deixando sequelas inesquecíveis.

Tomando por base os relatos das mulheres sobreviventes do Holocausto temos condições de reconstituir suas passagens pelos espaços de exclusão e extermínio enquanto recordações do que viram e sentiram. Os temas recorrentes são as fugas, as lutas pela sobrevivência, a fome, as perdas materiais e humanas, a saudade.

Entrevistar um sobrevivente e divulgar sua história de vida representa um engajamento, desde que essa narrativa acrescente novas informações para a história e memória do Holocausto, além de servir como referência para alertar as futuras gerações sobre os perigos das políticas racistas e a importância dos laços de solidariedade independente da etnia, religião ou partido político. Enfim, constatamos que localizar os sobreviventes e ter acesso às suas histórias de vida é privilégio de poucos. Por essa razão, este artigo pretende difundir tais narrativas, antes restritas ao universo familiar ou de algumas instituições com políticas de acesso não tão democráticas.

O conjunto de procedimentos da história oral empregado neste artigo, como metodologia de trabalho, para análise das entrevistas permite a verificação do impacto que as políticas racistas implementadas pelo Estado nazista e países colaboracionistas tiveram sobre a vida dessas mulheres. Sobretudo, no caso das legislações restritivas, de caráter antissemita, como as Leis de Nuremberg e 


\section{Arquivo Maaravi}

Revista Digital de Estudos Judaicos da UFMG

ISSN: $1982-3053$

outras ações que favoreceram a criação de espaços de exclusão e extermínio (guetos, campos de concentração, de trabalho, de prisioneiros e de extermínio).

Aspectos não revelados pela objetividade dos documentos escritos são observados pela análise das narrativas. Para o historiador Yehuda Bauer, uma grande quantidade de provas sobre o Holocausto foi destruída, então, uma das formas mais confiáveis para o estudo sobre o cotidiano dos guetos e dos campos de concentração nazista são os testemunhos dos sobreviventes.

Enquanto ferramenta didática, o uso dos registros orais, seja do Holocausto como de outros genocídios, é fundamental para aumentar a consciência pública sobre esses eventos, assim como os conflitos atuais. Algumas instituições investiram em projetos com história oral de sobrevivente, com o objetivo de "não esquecer jamais". O desafio para novos trabalhos com essa rede de colaboradores é estimular a fala sobre os aspectos narrativos que não foram contemplados nas compilações testemunhais oficiais, o que foi considerado como trivial, corriqueiro, da vida pessoal, afetiva, é único para cada indivíduo que pertencem à memória coletiva das minorias étnica afetadas pelo Holocausto.

\section{Horrores de um mesmo inferno}

A produção historiográfica sobre as políticas nazistas de controle de população e sexualidade aponta para o impacto na vida de mulheres e homens das diversas comunidades judaicas da Europa, principalmente para aqueles que foram deportados para os espaços concentracionários, à mercê do poder dos oficiais nazistas. A singularidade do estudo sobre as mulheres judias mostra que o grupo não era homogêneo, assim como a gama de experiências relatadas nas histórias de vida. Segundo a pesquisadora Myrna Goldenberg: “[...] those different horrors of the same hell". ${ }^{3}$

As mulheres judias e as ciganas (Sinti e Roma) foram submetidas a uma série de experiências médicas que visavam interromper o processo de reprodução destes dois grupos. Os procedimentos podiam ser fatais e irreversíveis, ocasionando transtornos e traumas permanentes. Tanto a esterilização como os abortos sem consentimento foram práticas comuns ao plano de Estado nazista de controle populacional e de higiene racial e devem ser avaliados como atos de domínio direto sobre o corpo e a vida sexual destas mulheres.

Em 1933, foi promulgada a Lei para Prevenção de Doenças Genéticas (Gesetz zur Verhutung Erbkraken Nachwuchses), editada por Wilhelm Frick (1877-1946), Ministro do Interior. O programa visava à esterilização de homens e mulheres 


\section{Arquivo Maaravi}

portadores de deficiências física e mental como esquizofrenia, epilepsia, cegueira, psicose maníaco-depressiva, transtorno bipolar e alcoolismo crônico. O líder da SS, Heinrich Himmler, (1900-1945), por sua vez, iniciou em 12 de dezembro de 1935, o programa Lebensborn (Fonte da Vida), com base nos princípios da higiene racial, destinados a reforçar a "raça ariana". O programa procurava impedir o nascimento daqueles que eram considerados inferiores e visava aumentar as taxas de natalidade dos indivíduos "superiores" da população. Ainda no ano de 1935 foram promulgadas as Leis de Nuremberg que excluíam os judeus alemães da cidadania do Reich e proibia-os de se casarem ou de terem relações sexuais com alemães arianos. De 1940 a 1941, foi implementado o programa de eutanásia por envenenamento provocado por gazes, operação que ficou conhecida como T4, abreviação para o endereço onde a prática era realizada, na rua Tiergartenstrasse 4, em Berlim.

O saber médico foi gradativamente transportado para os campos de concentração, espaços por no qual passaram algumas de nossas entrevistadas. Segundo a pesquisadora Ellen Ben-Seffer, o médico Viktor Brack (1904-1948) organizava as operações de esterilização e, a pedido de Heinrich Himmler, desenvolveu um método de intervenção com o uso de Raios X em larga escala. Em correspondência datada de 23 de junho de 1942, Brack relatava a Himmler que a produtividade dos prisioneiros judeus aumentaria se eles não tivessem suas capacidades reprodutivas normais. Estes procedimentos foram testados no campo de concentração de Auschwitz, sendo as evidências destes seus crimes julgadas pelo Tribunal de Nuremberg entre os anos de 1945 e 1946. Assim como a trajetória do médico ginecologista Carl Clauberg (1898-1957), capturado pelos russos e condenado pelas esterilizações provocadas nas prisioneiras de Auschwitz e do campo de concentração de Ravensbrück, que declarou "que seria capaz de esterilizar centenas, se não milhares de mulheres a cada dia". ${ }^{4}$

\section{Os bebês nos campos de concentração}

A gestação foi uma questão ambígua para os dirigentes nazistas, especialmente no caso da mulher judia, considerada como a reprodutora da raça inferior e portadora do sangue infecto dos judeus. As mulheres grávidas, se confinadas em guetos ou em campo de concentração, eram submetidas a diversos tipos de tratamento pelos oficiais. Nos campos de concentração de Ravensbrück e Auschwitz, um decreto proibia a admissão de mulheres grávidas e justificativa que os campos não tinham condições para as mulheres darem a luz. Se a gravidez fosse diagnosticada, certamente ocorreria o assassinato do bebê ou então a mãe seria submetida a experiências médicas de abortos - atos justificados pela ideologia nazista para barrar a reprodução de seres humanos 
racialmente inferiores. Nessa doutrina, no qual o objetivo era a aniquilação total da população judaica, homens e mulheres não tinham o direito a escolher o momento da sua própria reprodução, em suma, os direitos reprodutivos foram revogados aos judeus:

The number of children born or living in the camps will always remain a mystery, but a record of births in Ravensbrück from fall 1944 to April 1945 can give us a vague notion. The records tell us that 560 children were born, 23 women delivered prematurely, 20 hail stillborn babies, and 5 suffered miscarriages. For 266 children a date of deal li is given in the same book that records their birth. ${ }^{5}$

A maioria das crianças que nasceram em campos de concentração não sobreviveram pelas circunstâncias: fome, frio, fraqueza e debilidade das mães, pois muitas não amamentavam. Se a criança fosse descoberta pelos guardas do campo, certamente seria assassinada. Para os padrões sociais da Alemanha nacional-socialista, a maternidade é a plenitude da mulher: a criança trará felicidade à família, entretanto, em locais de tensão como os campos de concentração, esses sentimentos eram ambíguos. Observando a dimensão psicológica, a gravidez representava uma alegria, a esperança de dias melhores, de renovação e reforçava a vontade de viver entre as prisioneiras. Despertava sentimentos de solidariedade, de estratégias para manter a criança escondida o máximo possível. A sobrevivente do campo de concentração de Ravensbrück, Nomi Moskovits Friedmann, entrevistada por Rochelle Saidel, tinha sete anos quando foi deportada junto com seus pais e sua irmã de Amsterdam. Chegaram ao campo proveniente do campo de transição de Westerbork em novembro de 1943:

Nomi disse que as crianças ficavam com suas mães. Acrescentou que várias mães se revezavam vigiando as crianças enquanto as outras trabalhavam. Algumas delas morreram de doença ou foram assassinadas, e um grupo de mulheres se revezava para cuidar das órfãs. ${ }^{6}$

Em fevereiro de 1945, sua mãe Frida, junto com suas duas filhas, Nomi e Chaja, foram levadas para Bergen-Belsen. Após a libertação, retornaram para a Holanda onde reencontraram o pai, Ben Zion Moskovits, que também sobreviveu ao campo de concentração de Buchenwald. 


\section{Arquivo Maaravi}

A gravidez e os partos representavam a vida "normal", frente aos horrores da vida cotidiana dos campos de concentração. A pesquisadora Helga Amesberger analisou narrativas de mulheres que foram confinadas no campo de concentração de Mauthausen e Ravensbrück durante a gravidez. Sua pesquisa revelou uma série de sentimentos que incluem esperança, medo, tristeza, raiva, ódio, impotência, desamparo, vontade de fazer sacrifícios, amor, carinho, vergonha, desespero.

Em 2008, entrevistamos George Legmann, nascido em 8 de dezembro de 1944 em Landsberg. Sua mãe, Elisabeta Török Legmann, foi transportada grávida para o campo de concentração de Kaufering I - Landsberg, na Alemanha. Elisabeta era casada com Iosif Legmann e eles residiam na cidade de Cluj Napoca, na Romênia. Viviam relativamente bem até a ocupação nazista. A história de vida de Legmann é um dos raros casos em que as mulheres e as crianças conseguiram sobreviver.

“Em junho de 1944, os judeus da cidade foram deportados para Auschwitz Birkenau, campo de extermínio nazista na Polônia. Meu pai conseguiu fugir jogando-se do trem, perto de Budapeste, onde conseguiu se esconder. Valendose de seus conhecimentos em economia e por saber falar outros idiomas, conseguiu sobreviver ao Holocausto. No entanto, minha mãe, aos 29 anos de idade, não conseguiu escapar. Foi presa pelos nazistas. Ela, que já havia perdido dois filhos ainda em gestação, descobriu que estava grávida em 1944, quando já se encontrava no campo de trabalhos forçados de Kaufering I - Landsberg, na Alemanha. Quando desceu do trem, minha mãe e minha avó materna Regina, passaram por um processo de seleção, assim como todos os outros prisioneiros. Segundo minha mãe, os alemães disseram: 'Os velhos, os doentes e as grávidas vão para o caminhão. O resto vai a pé'. Sem saber que esse grupo seria enviado para as câmaras de gás, por serem considerados inaptos pelos nazistas, ela optou por seguir a maioria, e disse à mãe 'a senhora não é velha e eu não estou grávida.' As duas foram, então, enviadas para o campo de trabalhos forçados de Landsberg, onde permaneceram de dezembro de 1944 a maio de 1945. Minha avó Regina usava lenços na cabeça para esconder o cabelo branco e minha mãe, para esconder a gravidez, usava roupas largas durante o trabalho pesado e forçado no campo. Ela era uma mulher muito forte, tanto fisicamente quanto psicologicamente, e por isso sobreviveu. Conseguiu manter sua gestação. Até ser descoberta na penúltima semana. Os oficiais alemães ficaram surpresos e foram investigar se havia outras mulheres grávidas no campo. Encontraram em Landsberg mais seis mulheres grávidas. O mais provável seria a deportação para Auschwitz, mas com a proximidade do fim da guerra, ao final de 1944, os alemães estavam perto da derrota. O médico da SS ao pedir 


\section{Arquivo Maaravi}

instruções sobre o que fazer com as grávidas, recebeu como resposta 'faça o que quiser'. Segundo minha mãe, ao ver que a guerra estava no fim, o comandante do campo decidiu deixar as grávidas vivas, para que isso pudesse pesar a seu favor após a derrota. Após a guerra, continuamos a viver na Romênia, tentamos emigrar para os Estados Unidos, mas como tínhamos familiares no Brasil, optamos viver aqui."7

\section{Violência sexual durante o Holocausto}

A recente resolução 1.820, de 19 de junho de 2008, do Conselho de Segurança da ONU (Organizações das Nações Unidas), alerta para a violência perpetrada às mulheres em situações de conflitos internos e recomenda que essa prática deve ser punida como crime de guerra, além de advertir sobre as necessidades de apoio médico e indenizações às vitimas e detenção dos culpados.

Tais práticas, que ocorreram durante a Era Nazi, podem ser caracterizadas como parte do histórico dos crimes cometidos em guerras. O perpetrador sente prazer em dominar o corpo feminino sem o consentimento para o ato de violência. O objetivo de todas as formas de violação sexual é a demonstração de poder por meio da degradação e humilhação do outro. Em campos de concentração nazistas, a violência sexual foi observada em duas dimensões: uma atinge diretamente o corpo, como por exemplo, o estupro, o aborto forçado e as experiências médica; e a outra forma pode ser caracterizada como a violência indireta, que atinge a dimensão psicológica das prisioneiras, como, por exemplo, as ordens que as obrigavam à nudez pública sem consentimento, as deploráveis condições de higiene, o medo de apanhar, as ameaças e os insultos. Em entrevista concedida em 2008, Gabriella Fischer, húngara, narrou um momento dramático de violência.

"Chegou a nossa vez, eram oito mulheres, entre elas eu, minha mãe e a minha irmã. Saímos, tivemos que formar uma roda entre cada mulher uma fascista com um revólver. Nós tínhamos que nos abaixar com uma fascista atrás de nós, nas nossas costas e nos aliviar. Eu morria de vontade urinar, mas não saía uma gota da minha bexiga. A humilhação... eu me sentia violentada, eu me cobri e voltamos com as outras pessoas e é claro que eu não aguentei. O corpo, o frio, aquele ar corrente gelado, a roupa fria no corpo. Eu não podia urinar nas calças porque ia imediatamente se transformar em gelo, e a minha mãe estava com os olhos fechados. Eu a sacodia pensei que já estava morta. Porque a luz era meio verde claro, quase escuro. Eu falei 'mãe, não aguento mais', e ela disse 'você tem que urinar'. Então fomos mais uma vez, fizemos mais uma vez a fila, e aí eu já não me importava. Eu fiz o que precisava fazer em frente deles. Essa foi outra coisa que... tem tantas coisas marcam." ${ }^{8}$ 


\section{Arquivo Maaravi}

Revista Digital de Estudos Judaicos da UFMG

ISSN: $1982-3053$

Certamente, o estupro é uma das mais terríveis formas de violência sexual e deve ser compreendido segundo o contexto histórico-político de cada país. No genocídio de Ruanda e na Iugoslávia, a prática teve como objetivo a destruição étnica. Durante o regime nazista, os atos de violações não foram considerados como estratégia de guerra, mas como um ato de aniquilação das mulheres em campos de concentração e guetos:

[...] in wars, women "of the enemy" become the target of sexual violence because of their central significance for the construction and preservation of the ethnic-national group. The mass rape and forced pregnancies of the women of the enemy - such as the 1990 cases of Bosnian Muslim women in former Yugoslavia or the Tutsi women in Rwanda-demonstrate the extent to which the female body is seen is the "symbolic representation of the national body. ${ }^{9}$

Sobre os efeitos psicológicos em mulheres violentadas, lesões à sua integridade pessoal, danos emocionais e físicos, a ausência de justiça por parte da sociedade pode mitigar ainda mais o sofrimento das vítimas. Os tabus e a vergonha em falar sobre a violência sexual sofrida é uma barreira para estudos sobre este tema.

A violação tem origens na misoginia - manifestação de poder dos homens sobre as mulheres enraizados na tradição de sociedades patriarcais; ao mesmo tempo prova sua superioridade sobre a vítima. "Assim a violência sexual é a expressão de ódio às mulheres." 10 Em ambientes concentracionários, os guardas da $S S$ tinham pleno controle sobre as prisioneiras, mantendo a opressão, a exploração e os abusos.

O racismo, enquanto alicerce para a ideologia Nacional-Socialista, distinguia dois grupos: a raça superior e a raça inferior, indigna de se manter viva. Os grupos confinados nos campos e guetos eram classificados como da raça inferior e estavam sob constante vigília, aumentando a vulnerabilidade à violência sexual cometida por oficiais nazistas da SS e também por outros prisioneiros, em casos de campos de concentração mistos Auschwitz e Mauthausen.

Na entrevista de Rose Frochewags Mellender à Rochele Saidel, ela narra a sua passagem pelo campo de Malchow, e os fatores que ocorreram logo após a libertação pelos americanos e russos: 
Os russos chegaram e procuram algumas moças, sabe como é, fingimos que estávamos muito doentes para que não tocassem em nós. Eles eram uns animais, porque não tinham estado com uma mulher há muito tempo, pouco lhes importando se ela está em um campo de concentração, se está doente, se tem piolhos ou não. Não ligavam, e estupraram algumas moças. Por isso tivemos de nos esconder debaixo das camas e de outras coisas. Foi uma luta o tempo todo. ${ }^{11}$

Entre as diversas formas de violência sexual segundo relatos das sobreviventes, observa-se a nudez forçada para revista e desinfecção, quando essas mulheres precisavam ser identificadas para ingressarem nos campos de trabalho e extermínio, despiam-se geralmente observadas por oficiais da $S S$, perante familiares e os outros prisioneiros.

O uso de latrinas coletivas e a perda da capacidade de menstruar causaram tormentos físicos e mentais, muitas mulheres temiam a infertilidade $\mathrm{e}$ desconheciam os reais motivos da ausência do ciclo. Segundo a pesquisadora Brigitte Halbmayr, as condições de vida desastrosas nos campos de concentração, a falta de alimentos, o trabalho pesado, a imposição de torturas físicas reduzem a capacidade corporal, mantinha-se apenas o necessário para sobreviver:

Loss of the ability to menstruate, which almost all women experienced, also caused humiliation. At first many of them worried and were afraid they would be infertile as a result. That is why I consider the inability to menstruate as a form of sexualized violence. ${ }^{12}$

Outra dimensão da violência praticada nos campos era raspar os cabelos e os pelos do corpo das prisioneiras. Segundo os nazistas, essa medida visava conter infestações de piolhos - ato descrito pelas sobreviventes como uma prática de humilhação, punição e estigmatização. Segundo a sobrevivente judia, "Marta Kos said that shaving off her hair left "the deepest impression of all of the time spent in the concentration camp." 13

A pesquisadora Brigite Halbmayr observa que as vítimas de violência sexual durante o Holocausto estavam "condenadas" ao ostracismo, em virtude dos tabus que o tema despertava no contexto pós-guerra, e questões sobre o assunto raramente foram feitas. A demanda do período criava uma atmosfera de recomeço e luta para uma vida digna, o que impossibilitou que as mulheres 


\section{Arquivo Maaravi}

falassem sobre os abusos sofridos ou observados. A pesquisadora ressalta que não considera que os crimes sexuais foram as únicas preocupações das prisioneiras; a fome, a exaustão, o trabalho forçado, as doenças e as torturas também causavam transtornos fortes.

Poucos registros testemunhais abordam essa forma particular de sofrimento, sobretudo porque os nazistas eram oficialmente proibidos de manter relações sexuais com judeus em virtude da aplicação das Leis de Nuremberg. Se fossem detidos, o que raramente acontecia, seria pela prática de contaminação racial ou profanação da raça (rassenschande). ${ }^{14}$ Assim,

Há evidências, nos relatos e testemunhos históricos, de que essas leis eram infringidas com frequência. A maioria das sobreviventes não fala sobre sua própria exploração sexual, porém algumas contam histórias sobre o sofrimento de suas companheiras. A questão de gênero durante o Holocausto só começou a ser explorada 25 anos atrás, e sua significação ainda não foi resolvida. ${ }^{15}$

\section{$4 \mathrm{O}$ relato de Lola Anglister durante sua permanência em Auschwitz e Ravensbrück}

Lola Anglister nasceu na cidade de Cracóvia no dia 29 de outubro de 1925, filha de Yacob Rapaport e de Amália Luksner Rapaport. Seu avô paterno era Abraham Rapaport, sua segunda esposa era Rosa Rapaport. Seu pai e o avô Sholmo tinham uma loja de tecidos na cidade. Em 1939, Lola participou, com os jovens de sua escola, de uma colônia de férias onde se acidentou e quebrou a perna. Quando retornou para casa, a família não conseguiu atendimento médico em virtude da ocupação das tropas nazistas na cidade, um amigo da família, então, foi chamado e o socorro foi improvisado na mesa da cozinha.

"Me lembro que quando os alemães entraram na Polônia, começaram as perseguições aos judeus. Eles cantavam marchando na rua, contra judeus, em alemão, palavras que ainda me lembro. Fomos proibidos de estudar, e as escolas imediatamente fechadas e proibidas de aceitar alunos judeus, assim como a própria escola hebraica em que estudávamos." 16

Muitos refugiados judeus que saíram da Alemanha foram para Cracóvia. Para auxiliá-los, a comunidade judaica organizava cozinhas comunitárias, sua avó e sua irmã ajudavam na preparação. Lola recorda que, em comparação aos judeus alemães, a condição da família e dos judeus poloneses era bem melhor, pois ainda não haviam sido expulsos de suas casas, mas Lola não sabia das medidas 
que estavam por vir. Alguns meses depois, um dos quartos do apartamento da família foi requisitado pela polícia secreta alemã, e um oficial morou na residência por um tempo. Os judeus da cidade foram obrigados a usar a estrela amarela no casaco, e Lola presenciou nas ruas cenas de violência contra os judeus ortodoxos. Outra medida contra os judeus foi a obrigatoriedade de entregar casacos de pele, joias e dinheiro aos alemães, quem não o fizesse seria condenado à pena de morte. Em 1941, os judeus da cidade foram confinados no gueto, dentre eles, sua avó materna, o avô paterno e sua esposa. Abraham (seu avô paterno) faleceu, pois provavelmente já estava doente, e cinco meses depois seu pai também não resistiu ao sofrimento e faleceu.

Lola ressalta que não sabiam o que estava acontecendo no mundo exterior, não tinham notícia, o correio não funcionava, falavam em campos de trabalho em lugares distantes, e começaram a perceber que o gueto tem cada vez mais sua população diminuída. Restavam apenas as mulheres da família, que tiveram que cumprir mais uma ordem nazista: deixar o apartamento. Foram, então, para outra região do gueto, onde morava a sua tia Hana, irmã da mãe, que era casada e tinha dois filhos. Eram sete pessoas em um apartamento de dois quartos.

Em 28 de outubro de 1942, ocorreu uma grande ação no gueto, que quase foi liquidado. Lola trabalhava no aeroporto da cidade, e sua irmã trabalhava em uma fábrica de roupas para o exército dentro do gueto e sua mãe em uma fábrica de panelas. Houve a separação dos judeus, entre os aptos e os não aptos para o trabalho. Lola e sua irmã foram selecionadas, ela foi encaminhada para o aeroporto e sua irmã foi para outro local de trabalho. Sua mãe e sua avó provavelmente foram mortas na câmara de gás em Treblinka, informação que recebeu após o fim da guerra. Depois dos trabalhos forçados no aeroporto, Lola e os demais judeus foram deportados para campo de Plaszow. Lá reencontrou sua irmã e ambas passaram a realizar trabalhos forçados em uma pedreira. Presenciou cenas horríveis de crianças que foram arrancadas dos braços dos pais e levadas para campos de extermínio. Meses depois ocorre a deportação de Plaszow para o campo de Auschwitz:

“Fomos, então, levados pra estação e obrigados a subir em um trem, e fomos levados para Auschwitz. Não fomos nos vagões de passageiros, mas nos vagões fechados, de transportar gado, que ficaram superlotados. Mas minha irmã estava comigo. Chegamos, então, no campo de extermínio de Birkenau, onde, se não me engano, fomos cuidadas por meninas eslovacas. Tivemos que nos 
apresentar para ser feita uma seleção. Uma parte das meninas recebeu tatuagem e a outra parte foi posta de lado. Depois soubemos que, da parte colocada de lado, algumas meninas foram pra bordel, servir soldados alemães, e as outras meninas foram mandadas para $\mathrm{O}$ laboratório do Mengele. Eu fui tatuada com o número A26505, que somados todos os algarismos dá o número 18, mesmo valor da palavra chai, em hebraico, que simboliza 'vida' para os judeus. Minha irmã foi tatuada com o número A26504. E ela me disse: "Lola, você falou que vai sobreviver porque tem o número chai, 18".

Em Auschwitz, Lola e a irmã são obrigadas a trabalhar cortando madeiras e as colocando em carrinhos:
"Ainda no final do ano de 1944, nós fomos chamadas para o crematório. Ficamos paradas em frente ao lugar e tínhamos certeza de que eram nossos últimos momentos. Ficamos lá esperando por horas, até que chegou ordem para voltarmos. Não sabíamos o que havia acontecido, mas soubemos depois que o crematório estava superlotado, por isso fomos mandadas de volta."

No dia 18 de janeiro de 1945, ocorreu a chamada Marcha Forçada, ou Marcha da Morte, na qual os prisioneiros eram obrigados a caminhar longas distâncias, sem sapatos ou sem casacos sob a neve. Eram patrulhados por oficiais nazistas. Lola recorda que estava muito frio, caminharam por sete dias, quando chegaram ao campo de concentração de Ravensbrück:

“E então chegamos ao campo de Ravensbrück, na Alemanha. Era madrugada, mas o portão estava fechado e não nos deixaram entrar. Quando abriram pela manhã entramos em uma enorme tenda, superlotada de mulheres, e quando minha irmã sentava para descansar eu precisava ficar de pé, já que não havia espaço. Nesse campo passamos novamente por uma seleção, e de novo eu e minha irmã fomos selecionadas. Ficamos lá por dois ou três dias, e levaram-nos para um trem normal, diferente dos de antes."

Segundo a historiadora Rochele Saidel, "a maior parte das sobreviventes judias de Ravensbrück chegou depois Auschwitz foi evacuada em janeiro de 1945". ${ }^{17}$ 
As mulheres estavam debilitadas pelo trágico percurso, enfrentaram temperaturas abaixo de zero, e como narra Lola, o tempo de permanência nesse campo foi curto, algumas não se recordam da situação caótica dos últimos meses de funcionamento do campo, a maioria das prisioneiras foram deportadas para campos satélites.

Segundo as histórias de vida das sobreviventes, no campo de concentração de Malchow, as mulheres eram selecionadas para a fábrica de munições subterrânea. As que não conseguiram trabalho ficavam perambulando diante de condições de vida precárias, muitas morreram por doenças. O número de mulheres que participaram da marcha forçada para Malchow é impreciso, variava entre doze a vinte mil. ${ }^{18}$ Segundo a entrevista com Lola:

"[...] tinha cerca de trezentas mulheres, e dormíamos em beliches. Logo que chegamos fomos distribuídas para os trabalhos. Minha irmã e parte do grupo foram escolhidas pra trabalhar na fábrica de munição, que ficava a cerca de cinco quilômetros do campo, debaixo da terra, aonde se chegava através do bosque. Eu e outras meninas fomos escolhidas pra limpar a latrina e o esgoto que havia dentro do campo [...] trabalhei lá durante um tempo."

A sobrevivente Lola Anglister e sua irmã permaneceram nesse campo até a libertação pela Cruz Vermelha Internacional e de lá foram para Copenhagen, na Dinamarca. Estavam bastante debilitadas e pesavam menos de quarenta quilos. Posteriormente, foram para Lund, na Suécia, onde passaram por um processo de recuperação em um hospital local. Juntaram-se a um grupo Sionista e foram para Israel no final de 1947, onde Lola conheceu seu futuro marido, Moshe Anglister. Em 1950, nasceu a primeira filha do casal que, quando começou a andar, percebeu-se que tinha dificuldades e foi recomendada uma cirurgia. Como Israel estava em guerra, a situação financeira do casal estava bem precária. Lola, nesse período, recebeu uma herança do seu tio, o que auxiliou a família a procurar médicos para a filha. Seu marido conhecia o presidente da Federação Israelita da Alemanha, que indicou um médico em Munique onde a filha foi operada. Uma irmã de Moshe residia no Brasil e enviou a carta de chamada, chegaram ao Brasil em 1954, onde tiveram condições para recomeçar uma nova vida, segundo Lola, longe das guerras e dos traumas do passado.

As narrativas sobre as mulheres sobreviventes judias apresentam o testemunho da dor, da sensibilidade, da superação, da reconstrução da vida após o trauma e revelam a "frieza assustadora" dos perpetradores, tocando em pontos 
delicados, sobretudo sobre a vulnerabilidade de seus corpos diante da truculência.

A singularidade do relato feminino, as situações únicas vivenciadas por elas como, por exemplo, o recato diante da nudez forçada perante os oficiais nazistas, são questões que passam pelo universo do tormento físico e mental. Entendemos a opção de algumas mulheres nunca falarem sobre a violência sofrida, seja sexual ou observada. Registros como o diário de Mary Berg são importantes documentos históricos, que apresentam alguns fragmentos sobre a violência praticada pelos nazistas às mulheres no gueto de Lodz em 1939.

As narrativas abordam diferentes experiências marcadas pelas relações entre o espaço da casa e o espaço concentracionário de guetos e campos que são sempre traumáticos, além de apresentar a organização diante da ausência de familiares após o final da guerra e da libertação. Durante os anos do regime nazista, verificam-se as consequências do discurso produzido pelo Estado sobre as mulheres judias. Presente na fala dessas mulheres está a percepção que estavam sendo controladas e sabiam quais eram os estigmas que as caracterizavam como inferiores. Por exemplo, ter que usar a estrela de David amarela costurada no casaco.

A sobrevivência nos campos é narrada de forma trágica. As soluções para vencer a morte eram individuais. $\mathrm{O}$ pão, o cobertor, a caneca para a sopa, os sapatos são objetos únicos, insubstituíveis e raramente compartilhados. A luta pela sobrevivência é desafiadora, porque nos campos, os parâmetros de coletividade são vigiados. A arma poderosa dos nazistas é desestabilizar qualquer forma de organização coletiva que pudesse gerar alternativas de sobrevivência e resistência digna durante o período de confinamento.

As experiências narradas desconstroem a suposta fragilidade do sexo feminino, visto que as condições de trabalho nos campos eram similares à carga horária extenuante dos homens. A figura feminina se desenha de ressentimento e dor e transforma-se em coragem para manter-se, muitas vezes, sozinha em meio às perseguições. Se em casa a mulher protegia e cuidava dos filhos, no campo de concentração vêm à tona as dores, perdas, o silêncio, o rompimento com o hábito e com o conforto do lar.

Após 1945, o mundo toma conhecimento das barbáries praticadas pelos nazistas. Os efeitos da Segunda Guerra Mundial - além do número de mortos e das perdas materiais - certamente ficaram marcados nas lembranças daqueles que sobreviveram ao conflito que ganhou dimensões genocidas. Se as ações de repressão têm como medidas o contínuo deslocamento dos refugiados pelo 
mundo todo, os atos de salvacionismo e solidariedade podem ser recuperados através das vivências narradas pelos sobreviventes.

Lilian Ferreira de Souza é mestranda no Programa de Estudos Judaicos e Árabes - Departamento de Línguas Orientais - DLO- FFLCH/USP.

\section{Notas}

1 Conceito reabilitado e adaptado pelo nazismo na Alemanha: eram considerados racialmente inferiores os judeus, os ciganos e os negros. $\mathrm{O}$ homossexualismo, o lesbianismo, assim como as deficiências físicas ou mentais eram interpretados como sintomas de desvio. Do ponto de vista ideológico, eram perseguidos e excluídos os partidários de movimentos antinazistas, dentre os quais os, socialistas, os comunistas e todos aqueles contrários ao regime vigente como, por exemplo, os Testemunhas de Jeová.

${ }^{2}$ Importante ressaltar que, nem todas as mulheres entrevistadas são de origem alemã. Para esta pesquisa, em especial, procuramos avaliar e comparar as visões de mundo de mulheres judias de diferentes nacionalidades.

3 Aqueles horrores diferentes do mesmo inferno. (Todas as traduções deste artigo foram feitas pela autora.)

${ }^{4}$ HEDGEPETH, Sonja M.; SAIDEL, Rochele (Org.). Sexual Violence Against Jewish women during the Holocaust. Massachusettes: Brandeis University Press, 2010. p. 160.

${ }^{5} \mathrm{O}$ número de crianças que nasceram ou viveram nos campos será sempre um mistério, mas um registro de nascimentos em Ravensbrück do outono de 1944 a abril de 1945 pode nos dar uma noção vaga. Os registros nos dizem que 560 crianças nasceram, 23 mulheres com parto prematuro, 20 bebês natimortos, e cinco sofreram abortos. Para 266 crianças a data de morte é dada no mesmo livro que registra seu nascimento. AMESBERG, Helga. Reproduction under the Swastika. The other side of de nazi glorification of Motherhood. In: HEDGEPETH, Sonja M.; SAIDEL, Rochele (Org.). Sexual Violence Against Jewish Women during the Holocaust. Massachusettes: Brandeis University Press, 2010. p. 141.

6 SAIDEL, Rochelle G. As judias do campo de concentração de Ravensbrück. Tradução de Antonio de Pádua Danesi. São Paulo: Editora da Universidade de São Paulo, 2009. p. 87. 


\section{Arquivo Maaravi}

${ }^{7}$ Entrevista de George Legmann para Lilian Souza e Rachel Mizrahi - Núcleo de História Oral. São Paulo, 6 de maio de 2008. Acervo Arqshoah-LEER/USP.

${ }^{8}$ Entrevista de Gabriella Fischer para Lilian Souza e Rachel Mizrahi - Núcleo de História Oral. São Paulo, 12 de novembro 2008 Acervo Arqshoah-LEER/USP.

${ }^{9}$ Em guerras, as mulheres "do inimigo" tornam-se alvo de violência sexual por causa de sua importância central para a construção e preservação do grupo étnico-nacional. $\mathrm{O}$ estupro em massa e gravidez forçada das mulheres do inimigo, como os 1990 casos de mulheres bósnias muçulmanas na ex-Iugoslávia ou as mulheres tutsis em Ruanda demonstra a extensão em que o corpo feminino é visto, é a representação simbólica do nacional corpo. HALBMAYR, Brigitte. Sexualized Violence against Women during Nazi "Racial" Persecution. In: HEDGEPETH, Sonja M.; SAIDEL, Rochele (Org.). Sexual Violence Against Jewish Women during the Holocaust. Massachusettes: Brandeis University Press, 2010, p. 31.

${ }^{10}$ HALBMAYR, 2010, p. 31.

11 SAIDEL, 2009, p. 189.

${ }^{12}$ A perda da capacidade de menstruar, que quase todas as mulheres tiveram, também causou humilhação. No início, muitas delas preocupavam-se e tinham medo que seriam inférteis como resultado. É por isso que eu considero a incapacidade de menstruar como uma forma de violência sexual. HALBMAYR, Brigitte. Sexualized Violence against Women during Nazi "Racial" Persecution. In: HEDGEPETH, Sonja M.; SAIDEL, Rochele (Org.). Sexual Violence Against Jewish Women during the Holocaust. Massachusettes: Brandeis University Press, 2010. p. 34.

${ }^{13}$ Marta Kos disse que raspar os cabelos deixou "a impressão mais profunda de todo o tempo gasto no campo de concentração". HALBMAYR, Brigitte. Sexualized Violence against Women during Nazi "Racial" Persecution. In: HEDGEPETH, Sonja M.; SAIDEL, Rochele (Org.). Sexual Violence Against Jewish Women during the Holocaust. Massachusettes: Brandeis University Press, 2010. p. 36.

${ }^{14}$ GOLDENBERG, Myrna. Sexo, violación y supervivencia. La mujer judía e o Holocausto. In: Nuestra Memória. Buenos Aires. Publicacion del Museo Del Holocausto, año XVI, n. 34, Diciembre 2010. p. 270.

${ }^{15}$ SAIDEL, 2009, p. 39.

16 Entrevista de Lola Anglister para Luba Schevz e Ana Duarte - Núcleo de História Oral Arqshoah. São Paulo, 1 de setembro de 2011. Acervo Arqshoah LEER/USP.

17 SAIDEL, 2009, p. 141.

18 SAIDEL, 2009, p. 187. 


\section{Referências}

ADORNO, Theodor W. Educação e Emancipação. Tradução de Wolfgang Leo Maar. São Paulo: Paz e Terra. 2006.

AMESBERG, Helga. Reproduction under the Swastika. The other side of de nazi glorification of Motherhood. In: HEDGEPETH, Sonja M.; SAIDEL, Rochele (Org.). Sexual Violence Against Jewish Women during the Holocaust. Massachusettes: Brandeis University Press, 2010. p. 139-159.

BOCK, Gisela. A politica sexual nacional-socialista e a história das mulheres. In: DUBY, Georges; PERROT, Michelle (Org.). História das mulheres no ocidente. O século XX. Lisboa: Edições Afrontamento, 1991. p. 185-218.

BOSI, Eclea. Memória e sociedade. Lembranças de velhos. São Paulo: Companhia das Letras, 1994.

CARNEIRO, Maria Luiza Tucci. Brasil, refúgio nos trópicos. São Paulo: Estação Liberdade; Instituto Goethe, 1997.

CARNEIRO, Maria Luiza Tucci. Cidadão do mundo: o Brasil diante do Holocausto e dos judeus refugiados do nazifascismo. São Paulo: Perspectiva: FAPESP, 2010.

GOFFMAN, Erving. Estigma notas sobre a manipulação da identidade deteriorada. Tradução de Márcia Bandeira M. L. Nunes. Rio de Janeiro: Zahar Editores, 1975.

HALBWACHS, Maurice. Memória coletiva. São Paulo: Centauro, 2006.

HOBSBAWN, Eric J. Era dos Extremos: o breve século XX - 1914-1991. Tradução de Marcos Santarrita. São Paulo: Companhia das Letras, 1995.

MATOS, Maria Izilda Santos. Âncora de emoções: corpos, subjetividades e sensibilidades. Bauru: Edusc, 2005.

PATAI, Daphne. História oral, feminismo e política. São Paulo: Letra e Voz. 2010. MEIHY, José Carlos Sebe. Manual de história oral. São Paulo. Edições Loyola. 1996. 
PERROT, Michelle. Os excluídos da história: operários, mulheres e prisioneiros. Tradução de Denise Bottmann. Rio de Janeiro. Paz e Terra, 1988.

POLIAKOV, Léon. O mito ariano. São Paulo: Perspectiva; Edusp, 1974.

SAIDEL, Rochelle G. As judias do campo de concentração de Ravensbrück. Tradução de Antonio de Pádua Danesi. São Paulo: Editora da Universidade de São Paulo, 2009. 